\title{
Time Speeds Up During Flow States: A Study in Virtual Reality with the Video Game Thumper
}

\author{
Hans Rutrecht ${ }^{1}$, Marc Wittmann ${ }^{2}$, Shiva Khoshnoud ${ }^{2}$ and \\ Federico Alvarez Igarzábal ${ }^{2, *}$ \\ 'Institute of Psychology, University of Freiburg, 79085 Freiburg, Germany \\ ${ }^{2}$ Institute for Frontier Areas of Psychology and Mental Health (IGPP), 79098 Freiburg, Germany
}

Received 24 September 2020; accepted 30 March 2021

\begin{abstract}
Flow is a mental state characterized by deep absorption during challenging activities, which was first studied by Mihaly Csikszentmihalyi. One of the defining characteristics of this state is the loss of the sense of time. Despite the widespread scientific interest in flow, there are few quantitative studies specifically on the aspect of time perception. The present study focuses on the relation between time perception and flow states in the context of video game play. Participants $(n=100)$ played the rhythm game Thumper for 25 minutes in one of two conditions: in virtual reality (VR) or on a computer screen (2D). Participants who played the game in VR performed better and had a stronger feeling of presence than those who played in 2D. Thumper was flow-inducing regardless of condition and the more flow participants experienced the less they thought about time and the faster time passed subjectively. The total score obtained by players as an objective measure of player performance was positively correlated with flow states, indicating that the more flow participants experienced, the better they played.
\end{abstract}

Keywords

Flow, time perception, video games, virtual reality, duration estimation, presence

\section{Introduction}

Back in the 1970s, psychologist Mihaly Csikszentmihalyi described a state of optimal experience that can be elicited by activities that have clear goals, can be completed, and provide immediate feedback (Csikszentmihalyi, 2009, p. 49). This

\footnotetext{
* To whom correspondence should be addressed. E-mail: alvarez@igpp.de
} 
mental state is characterized by deep concentration, effortless involvement, a sense of control, and the loss of the senses of time and self (ibid.). Csikszentmihalyi famously called this state flow. Chess and football players, dancers, climbers, assembly line workers, and meditators can all experience flow while entranced by their activities.

Importantly, a state of flow is a point of equilibrium between anxiety and boredom. If an activity provides a level of challenge that is too low relative to the skill level of the person performing it, the person will become bored. If, on the other hand, the challenge is too high relative to the individual's skill level, they will become anxious. The flow state ensues when the level of challenge of the activity meets the skill level of the person (Csikszentmihalyi, 2009, p. 74). In this sense, flow is related to what we colloquially call 'enjoyment' or 'fun'. Therefore, as your skills improve in any activity, you will seek to increase the challenge accordingly in order to keep experiencing flow - if you are a climber you will move on to ascend more demanding rock formations; if you are a chess player, you will seek to play against more skillful opponents; and so on. Flow states are also associated to a successful performance and feelings of competence (Engeser et al., 2005; Jin, 2012; Weibel et al., 2012), since a task that is too difficult would lead to frustration and a task that is too easy can lead to diminished concentration, resulting in a suboptimal execution and lack of flow in both cases.

Flow has been the object of abundant research in psychology. Csikszentmihalyi identified the components of flow listed above through a series of qualitative studies (Csikszentmihalyi, 2000). To study flow quantitatively, Csikszentmihalyi developed the Experience-Sampling Method (ESM), which consists primarily of asking participants questions about their mental state at different moments throughout the day (Larson \& Csikszentmihalyi, 2014). To this end, participants carried a signaling device (e.g., a pager). Whenever this device emitted a signal, participants had to fill out an Experience-Sampling Form (ESF; Csikszentmihalyi \& Larson, 2014, pp. 37-38) with items that could vary depending on the study. As Rheinberg and coworkers (2003) point out, the items on the ESF do not address all of the components of flow. Most importantly in the context of this study, the ESF lacks items concerned with subjective time. The ESF assesses, among other things, current mood, what the subject was doing before receiving the signal, and the social context of the activity. Concerning the direct components of flow, the ESF asks about the relation between challenge and skill (ibid.). The ESM was optimized with items that address the components of the flow experience more directly by, among others, Jackson and Marsh for the context of sports (Jackson \& Marsh, 1996), and by Rheinberg and coworkers with the Flow Short Scale for a broad range of activities (Rheinberg et al., 2003). There are also a few models of flow adapted to the context of human-computer interaction (Agarwal \& Karahanna, 2000; Ghani \& Deshpande, 1994; Hoffman \& Novak, 1996; Trevino \& Webster, 
1992; Webster et al., 1993). Agarwal and Karahanna (2000) propose the concept of 'cognitive absorption', but we employ the term 'flow', since it is more common in video game research.

It is known that altered states of consciousness, such as those induced through psychological induction techniques or by the intake of pharmacological agents such as psilocybin and LSD, can lead to a diminished sense of self and time (Wittmann, 2015, 2018). The experience of flow is a feature of altered states of everyday consciousness related to a diminished sense of time but, to our knowledge, little has been done to study its quantitative effects on time perception in experimental settings. Nuyens and coworkers (2020) reviewed the literature on how video games can affect time perception, with a special focus on gaming disorder. The review analyzes cognitive and emotional factors, and the state of flow. The authors remark that "although there is a lack of studies examining the causal link between enjoyment and time perception, it appears plausible that having fun leads to underestimating time duration" (ibid., p. 14). Additionally, time perception is sometimes not even assessed by flow scales and, if so, the items can occasionally be vaguely formulated. Jackson and Marsh's (1996, p. 35) scale uses four items: "Time seemed to alter (either slowed down or speeded up)"; "[t]he way time passed seemed to be different from normal"; "[i]t felt like time stopped while I was performing"; and "[a]t times, it almost seemed like things were happening in slow motion". This scale does not clearly differentiate between time slowing down and speeding up and it does not quantify how fast or slowly time passed in the participant's experience. Rheinberg et al.'s (2003) Flow Short Scale assesses time perception with only one item: "I don't notice time passing". This one item is insufficient to assess if and how fast or slowly time passed in the participant's experience. Even though a stronger focus on the passage of time leads to time slowing down (Zakay \& Block, 1997), the item still does not directly assess what exactly the participant experienced. Agarwal and Karahanna's (2000) Cognitive Absorption model, which is related to flow, assesses time perception with the following items: "Time appears to go by very quickly when I am using the Web"; "Sometimes I lose track of time when I am using the Web"; "Time flies when I am using the Web"; "Most times when I get on to the Web, I end up spending more time that I had planned"; and "I often spend more time on the Web than I had intended". These questions ask if time passed fast, but do not adequately quantify how fast (or slowly).

To adequately measure the experience of the passage of time, questionnaires should quantify how fast time passes for each participant and if they thought about the passage of time often or not at all. Additionally, participants should be asked for an estimation of how much time elapsed (though, as explained later, this question has a limitation). The attentional-gate model (AGM; Block \& Zakay, 1997; Zakay \& Block, 1997), based on an original pacemaker-accumulator model (Treisman, 2013), provides a rationale for changes in the perception of time. In 
this model, an internal clock consists of a pacemaker that emits signals continuously during a given interval which are counted by an accumulator. The number of accumulated signals is stored in memory and can be used to represent the duration of that interval. According to the AGM, time signals are only registered when attention is actually directed to the passage of time (which is why it is important to ask participants how often they thought about the passage of time). In relating this model to the experience of flow when one is absorbed in an activity like playing a video game, decreased attention to time leads to a decreased inflow of pulses. Accordingly, time flies during an entertaining gaming session and duration is underestimated. In contrast, boredom is a situation when one attends to time, which leads to time passing slowly and an overestimation of duration (Jokic et al., 2018; Witowska et al., 2020).

An interesting series of studies by Christandl and coworkers showed that manipulating the experience of time of participants can have an effect on their report of flow experiences (Christandl et al., 2018). In these studies, participants were told that they would have to perform a task for either five minutes ('time drags condition') or 15 minutes ('time flies condition'). But the task was actually, unbeknownst to the subjects, always 10 minutes long. This manipulation affected the level of reported flow. Those in the 'time flies' condition (in which 15 minutes seemed to pass subjectively very quickly, since the time interval objectively lasted 10 minutes) reported experiencing a faster passage of time and more flow, and performed better in a subsequent task.

\subsection{The Study}

The present study focuses on time perception in flow states in the context of video games and virtual reality. Csikszentmihalyi and Rathunde (1992) stated that most games provide clear goals and feedback and Privette (1983) argued that game playing is a prototypical flow activity (in Keller \& Bless, 2008). The medium of the video game specifically is well known for making time fly, which is one of the main aspects of flow (Bisson \& Grondin, 2013; Bisson et al., 2012; Luthman et al., 2009; Rau et al., 2006; Sanders \& Cairns, 2010; Tobin \& Grondin, 2009; Tobin et al., 2010; Wood \& Griffiths, 2007; Wood et al., 2004, 2007). In a survey by Wood and coworkers, for instance, $99 \%$ of respondents reported losing track of time when playing video games (Wood et al., 2007). Experimental studies have also shown that people tend to lose track of time while playing video games (Bisson \& Grondin, 2013; Bisson et al., 2012; Luthman et al., 2009; Rau et al., 2006; Tobin et al., 2010; Tobin \& Grondin, 2009).

Flow has been widely discussed in both the game design (Baron, 2012; Chen, 2006; Salen \& Zimmerman, 2003; Schell, 2008) and game studies literature (see for example Alvarez Igarzábal, 2019, 2020; Ermi \& Mäyrä, 2005; Faiola \& Voiskounsky, 2007; Keller \& Bless, 2008; Michailidis et al., 2018; Shernoff 
et al., 2014; Sweetser \& Wyeth, 2005; Sweetser et al., 2012; Takatalo et al., 2010; Voiskounsky et al., 2004; Weibel \& Wissmath, 2011).

Game designers like Schell (2008) and Salen and Zimmerman (2003) discuss flow theoretically due to its relevance to video games in their books aimed to inform game designers. The authors point out how video games seem to meet all the criteria for flow-inducing activities, since they typically provide clear goals and immediate feedback, and can be completed (or at least offer tasks that can). Chen (2006) develops an informal theory for the implementation of flow in game design through what he calls Dynamic Difficulty Adjustment (DDA). By adapting the difficulty of the game to the skill level of the player, Chen argues, the experience of flow becomes more likely.

The analyses of flow in the game studies literature are both theoretical and empirical, which reflects the interdisciplinary nature of the field. Alvarez Igarzábal (2019, 2020) discusses flow in his theoretical examinations of time in video games, as it is one of the main factors that can alter the experience of the passage of time for a player. Ermi and Mäyrä (2005) propose a gameplay experience model that analyzes three dimensions of immersion: sensory, challenge-based, and imaginative immersion. Challenge-based immersion is related to the experience of flow. Voiskounsky and coworkers (2004) and Faiola and Voiskounsky (2007) conducted surveys among Multi-User Dungeon (MUD) players with a specifically designed questionnaire aimed at assessing the players' motivations. In both studies, flow was found to be one of the motivating factors. Sweetser and Wyeth (2005) developed the GameFlow model, a tool that designers can use to analyze the potential entertainment value of their game. This model, as its name indicates, is heavily based on Csikszentmihalyi's notion of flow. Later, Sweetser et al. (2012) revisited the model to create a version specifically aimed at real-time strategy games. Shernoff and coworkers (2014) adapted the ESF (Hektner et al., 2007) and a psychometric survey developed by Nunnally (1978) to measure flow while playing educational games, in order to assess the influence of flow in gamebased learning.

There is also a body of research that analyzes flow in video games with relation to the concepts of presence, involvement, and immersion. Takatalo et al. (2010) developed the Presence-Involvement-Flow Framework (PIFF), a questionnaire aimed at assessing player experience along the three titular dimensions. Weibel and Wissmath (2011) conducted three studies that examined the relation between presence and flow. The results of these studies show that these are distinct concepts that share little common variance. Michailidis and coworkers (2018) review numerous studies on presence, immersion, and flow in video games. They argue that the literature often confounds immersion and presence, but also add that flow and immersion can be seen as altered states of consciousness, while presence does not exhibit the same characteristics. Presence, so the authors claim, would be an earlier stage of engagement with video games than immersion or 
flow. Given the varied conceptualizations of the notions of immersion, presence, and involvement, and how the terms can often be confounded, it is challenging to provide clear definitions (Jennett et al., 2008; Michailidis et al., 2018). For the purpose of this study, we will use the notion of presence as characterized by Schubert and colleagues (2001) through two components: "the sense that we are located in and act from within the [virtual environment], and the sense that we are concentrating on the [virtual environment] and ignoring the real environment". We eschew the terms of immersion and involvement for the sake of clarity.

With regard specifically to the quantitative examination of time perception and flow in video games, we could only find one study by Keller and Bless (2008), but its main focus was intrinsic motivation and time perception was assessed with only one item - namely by asking participants to indicate how long the play time was on a 10-cm long horizontal line that ranged from 'very short' to 'very long'. This study showed that participants who played a version of the video game Tetris that adapted to their skill level estimated the play time to be shorter and rated higher on other measures of flow than participants who played an easy or a hard version of the game. These results support Chen's aforementioned DDA method for inducing flow (Chen, 2006).

But video games come in many forms (e.g., action, strategy, role-playing, simulation), and different people might enjoy different types of games. This means that, to test flow in gaming, the safest ways to proceed would be to either allow participants to play their favorite game or game genre (cf. Tobin et al., 2010), or choose a specific game that possesses characteristics that make it likely to elicit flow in most players. Since we were not aiming to test gamers only, we settled for the latter.

The game we chose for this study was Thumper (more on the rationale behind this choice in the next section). Our first objective was to quantitatively assess the perception of time in relation to experienced flow states when playing Thumper. Methodologically speaking, two types of experimental designs for assessing subjective time exist. In a prospective design, a subject is aware beforehand that time has to be estimated (e.g., the duration of the game). In our study, however, we wanted to capture a more natural situation when a player realizes how much time has passed after playing for a while. Therefore, we employed a retrospective design, i.e., we asked the subject about the experience of time only after they had played the game (Block \& Zakay, 1997; Tobin et al., 2010). In addition, we wanted to compare two different conditions: while half of the people played the game on a screen (2D), the other half played it in virtual reality (VR) using a head-mounted display. Given that VR can induce a strong sense of presence in the virtual world - through the use of head-mounted displays and by incorporating bodily movement into the interaction (Schubert, 2003; Schubert et al., 2001) - we also aim to assess if presence could be linked to the state of flow and the experience of the passage of time, as well as to performance indices in gameplay (cf. Weibel \& Wissmath, 2011). 


\section{Materials and Methods}

\subsection{Choosing the Game}

There is no gold standard when it comes to eliciting flow with video games, but we argue that some features can make games more likely to do so, especially when it comes to players with little to no gaming experience and in a short gaming session. Such a game would have to possess the following characteristics:

(1) A game of skill: Often when video games focus primarily on storytelling, the level of motor skills required to interact with them is very low. This is not to say that narrative games cannot elicit a state of flow, but in storytelling personal taste is arguably a stronger factor that can affect the enjoyment of a game. Games of skill seem thus more likely to engage a wider audience.

(2) Easy to learn but difficult to master (see Note 1): Interaction with the game should be easy enough that anyone with full mental and bodily capacities would be able to start playing right away. Since skills can vary greatly from person to person, it is important that the game provides depth to its mechanics in a way that capable players can push themselves harder than less skilled players (cf. Chen, 2006; Klarkowski et al., 2015). Systems that automatically adapt the level of challenge of a game to the skill of the player according to their performance - such as DDA (Chen, 20o6) - were also taken into account, but did not constitute a necessary criterion.

(3) Unavoidable challenges: In many games, the player needs to actively navigate the game space to meet the challenges and can even ignore them if the game provides enough freedom. We wanted challenges to come to the player, so that our study would not need to rely on the player's motivation to seek them out. For this reason, if the game involved the control of entities (e.g., an avatar, puzzle pieces) that navigate through space, we wanted this navigation to happen automatically.

(4) Fixed camera and focused action: We looked for games that do not require players to move the camera to seek for relevant stimuli, since this feature can prove disorienting for inexperienced players. We chose to look primarily for games where the camera is fixed and action requires that the player focuses only on a specific section of the screen.

Since we did not want to limit our sample to experienced gamers, we looked for a game with the characteristics listed above. Of course, the game had to fulfill the requirements listed by Csikszentmihalyi as well: clear goals, possibility of completion, and immediate feedback (Csikszentmihalyi, 2009). Fortunately, these three characteristics are easy to find in video games. A final aspect that was important 
for this particular study was that the game should be playable both in VR and on a computer screen, since we wanted to compare these two conditions. After a brief pre-study in which we considered some alternatives, we settled for the game Thumper (Fig. 1), developed by the studio Drool and released in 2016.

\subsection{Thumper}

Thumper is a rhythm game, meaning that players need to press buttons on the controller in sync with the soundtrack and visual animation to perform in-game tasks. Poor timing leads to a lower score, which makes it a game of skill (point 1). The player controls a silver beetle that moves forward automatically (point 3) on a track in an abstract, lysergic landscape. As the beetle advances, the player needs to react to obstacles and interactive elements on the track. The camera is located behind the beetle facing forward, allowing the player to see the obstacles ahead (point 4). The game is divided into nine different levels, each of which is subdivided into different sections (e.g., level 1 has 15 different sections and level 2 has 22).

The mechanics of Thumper are easy for newcomers: press the action button ' $\mathrm{A}$ ' (when using an Xbox controller) when the beetle is on top of one of the lights that are placed on the track, and either ' $\mathrm{A}$ ' or a simple combination of 'A' and a direction on the left analog stick (e.g., 'A' + left) to overcome certain obstacles like sharp curves or spikes. Even though the mechanics are simple enough, the challenge arises from reacting to the barrage of stimuli racing toward the player. Better players can aim for higher scores (point 2) by, for instance, doing 'perfect

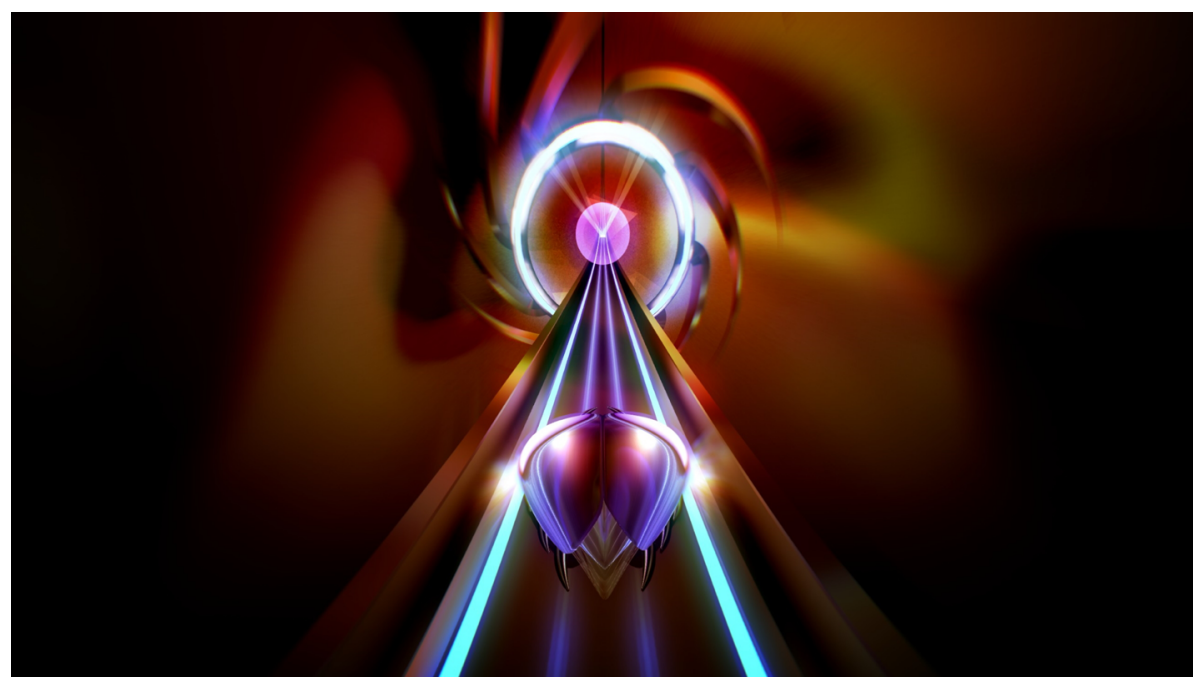

Figure 1. Thumper, (C) Drool LLC 2013-2019. Reproduced with permission from the developers. 
turns' by starting to turn just before a curve (turning earlier is safer, but grants fewer points), or hitting more blue lights, which only grant points and can thus be missed without hampering progress if the player is overwhelmed. Hitting streaks of blue lights adds multipliers that increase the amount of points obtained per light, which provides an extra challenge for experienced players.

Thumper also fulfills the requirements of clear goals, possibility of completion, and immediate feedback characteristic of flow activities. The game provides the explicit goal of surmounting obstacles to navigate the track from beginning to end while accumulating as many points as possible. These goals are made clear through the game's visual representation of the player character, the track, and the obstacles; tutorial sections that show how to deal with said obstacles; and by showing clearcut ends of levels and level sections that inform the player of their score and give them a rank (from best to worst: S, A, B, and C). Thumper emphasizes the possibility of completion already on the menu, which shows that it is composed of a finite set of levels. During gameplay, it signals level section endings with rings that surround the track and by showing the score and rank obtained in that level section. Level endings are marked by a final boss fight with the level section name $\Omega$ (all other level sections are numbered). After the boss is defeated, the screen fades to black and the final score and rank for the level are provided. The immediate feedback is provided in the form of visual and aural output as a response to the player's button and analog stick presses in the movements of the beetle, which can swing left and right, and open its wings and jump. The interaction with obstacles and lights is emphasized by different animations and sounds, which signal successful and failed attempts - e.g., when missing a light, a buzzer sound plays and a red light flashes on the track.

\subsection{Participants}

This study tested 100 participants (50 males and 50 females, 25 of each per condition: VR, 2D) between 18 and 35 years of age. Due to a screening error, one 47-year-old male participant took part in the experiment. He was included in the final analysis. On average, participants were 25.1 years of age (SD: 4.6). Separately for the two conditions: $2 \mathrm{D}$ : mean $=24.8(\mathrm{SD}=4.9)$; VR: mean $=25.3(\mathrm{SD}=4.2)$. This small age difference is not significant $\left(t_{98}=-0.48, p=0.632\right)$. Overall, the level of education was high, with $32 \%$ of the participants having a university degree, 66\% a high-school diploma (the Germans Abitur and Fachabitur) and 2\% a Realschulabschluss, a German school diploma that does not grant access to university. The vast majority were students of the University of Freiburg, recruited through two online platforms (Freiburg Psychological Department, Student Services University Freiburg), flyers, word-of-mouth dissemination, and from other studies at the Institute for Frontier Areas of Psychology and Mental Health. 
We screened prospective participants over the telephone to determine if they fulfilled the requirements to take part in the experiment (age, German proficiency, mental health, medication) and ask them about their gaming experience. Only ten participants (10\%) reported having tried VR at least once, whereas the rest (90\%) had no prior experience with this technology. Sixty-nine participants reported playing video games regularly (once a week or more) and had played in the last six months, or had played regularly in some period of their lives. The remaining 31 participants reported never having played a video game before or playing less than once a week and not playing in the past six months. We classified the former group as 'gamers' and the latter as 'non-gamers'. Each participant was awarded $€ 10$ for their participation. This study was approved by the local ethics committee of the Institute for Frontier Areas of Psychology and Mental Health (IGPP_2019_01).

\subsection{Materials}

The chosen video game, as explained above, was the rhythm game Thumper. Participants in both the VR and 2D conditions played the game with an Xbox One controller on a Windows 10 PC. We chose to use the same input device in both conditions (instead of using the VR headset's hand controllers in the VR condition) to avoid confounders. The PC's specifications comfortably surpassed the recommended requirements to run Thumper smoothly - recommended requirements: Intel i5-6400 processor, 8 GB RAM, GeForce GTX 970; actual PC specs: Intel i7-9700K processor, 16 GB RAM, GeForce RTX 2080Ti. The copy of Thumper used in the experiment was purchased and installed via the gaming platform Steam. Participants in the 2D condition played on a 27-inch Asus PB278QR LCD computer screen (display resolution: $2560 \times 1440$ pixels) at a resolution of 1920 $\times 1080$ pixels. Participants in the VR condition played with the Oculus Rift S headmounted display (HMD). In VR the game was run at a resolution of $1280 \times 720$ (both the VR and $2 \mathrm{D}$ resolutions used are set by Thumper by default). In both cases, participants used Sennheiser CX300S in-ear headphones to listen to the game's sound and music.

We used a number of trait and state questionnaires in the study. To measure the level of flow (or lack thereof) after the play session we used the Flow Short Scale (FSS) developed by Rheinberg and coworkers (Rheinberg et al., 2003). We used the mean score of the 10 FSS items with seven-point Likert scales as answer category, ranging from 1 (not at all) to 7 (very much). To assess if participants found the game easy or hard we used item 14 of the FSS ("Compared to all other activities which I partake in, this one is ...” which participants answer on a Likert scale ranging from 1, 'easy', to 9, 'difficult'). We singled out this variable because flow states arise when the performed activity is not too easy and not too hard, so participants who experience high levels of flow with Thumper should rate its difficulty toward the center of the scale. The Swedish Flow Proneness Questionnaire (SFPQ; Ullén et al., 2012) was implemented to measure the subject's tendency 
to experience flow. We recorded each participant's gameplay to extract measures of performance, namely their total score and which level and level section they reached. Since flow is often associated to adept performance (Engeser et al., 2005; Jin, 2012; Weibel et al., 2012), one should expect participants to attain higher scores and reach higher levels the more flow they experience.

To assess the effects of the gaming session on time and bodily perception we implemented the Subjective Time, Self, and Space (STSS) questionnaire (Jokic et al., 2018). We partly adapted three items from the STSS to assess the experience of the passage of time: (1) "Intuitively, without thinking about it, the gameplay session lasted __ minutes and __ seconds;" (based on Tobin et al., 2010); (2) "how often did you think about time?"; and (3) "how fast did time pass?" The two last questions were answered with a vertical streak on a $10-\mathrm{cm}$ long horizontal line (visual analog scale) that ranged from 'not at all' to 'a lot' on question two and from 'very slowly' to 'very fast' on question three. Participants were not told beforehand that they would have to estimate the duration of the play session, which means that the paradigm was retrospective - as opposed to prospective, when participants know that they will need to estimate the duration of a task (Block \& Zakay, 1997; Zakay \& Block, 1997).

We phrased question one in a way that would hopefully appeal to the participants' intuition. Video games are well known for making time fly, so participants could use this knowledge to estimate their answers and counterbalance their subjective feeling of time passing faster (assuming they had this experience in the first place). By asking them to give an estimate "intuitively, without thinking about it," we hoped to reduce this counterbalancing effect (cf. Tobin et al., 2010). We also asked this question before the other two so that they had less time to reflect on their subjective experience. The second question - "how often did you think about time?" - relates to Zakay and Block's (1997) AGM, which states that paying attention to the passage of time makes it slow down in experience. A typical example of this phenomenon is our experience of waiting rooms, where the lack of stimuli draws our attention to the fact that we are waiting and thus to time - a scenario that has been tested experimentally (Jokic et al., 2018; Witowska et al., 2020). The third question - "how fast did time pass?" - is meant to assess if participants have a feeling that the gameplay session went by faster in their experience than in terms of an objective time.

The STSS measures the intensity of awareness of the bodily self with a nonverbal pictorial scale with the answer category ranging from 1 to 7 . The question used was: "How intensively did you experience your body most of the time?"

We used the Simulator Sickness Questionnaire (SSQ; Kennedy et al., 1993) to measure potential symptoms of motion sickness produced by the interaction with the game. While there are newer instruments to measure cybersickness in VR specifically (Sevinc \& Berkman, 2020), these must still be sufficiently validated. The Igroup Presence Questionnaire (IPQ; Schubert et al., 2001) was implemented to determine the level of presence experienced by subjects while engaged with the 
game's virtual environment. We also used the Self-Assessment Manikin (SAM; Bradley \& Lang, 1994) scale, which directly measures subjective responses including (a) positive vs negative valence, and (b) an individual's arousal level. We implemented the five-point version of the scale. The two SAM scales were assessed before and after the period of gaming.

Finally, we also asked participants if they had already played Thumper before (to which they had to answer 'yes' or 'no') and if they liked the game (with a sevenpoint Likert scale: $1=$ not at all, $7=$ very much).

\subsection{Procedure}

Upon arrival at the institute, participants were briefed about the details of the study and asked to sign a consent form. Through a questionnaire that assessed their momentary wellbeing, we determined if the person was in condition to take part in the experiment. Participants were then asked to fill out the SFPQ, SAM, and SSQ. The experimenter explained the gameplay basics of the video game Thumper with a brief instruction manual created specifically for the study. Afterwards, participants played a training session that consisted of the first six sections of level one. The experimenter sat next to the participant and observed their performance to make sure that they understood how to play. Once the training ended, participants played Thumper for 25 minutes starting again from the beginning in one of two conditions: in VR or on a computer screen (2D). Participants were randomly assigned to one of the two conditions (intersubject design). During the gaming session, the experimenter remained in the room just in case the participants experienced any complications, but moved to the side and did not observe the participant's performance. It was also important that the experimenter stayed in the room in case participants finished the first level, because navigating the menus to move on to level two quickly can be unintuitive for new players. Participants were thus instructed to tell the experimenter if and when they finished level one, so that they could start playing level two without losing much time. The 25-minute gaming session was recorded with the software Plays.tv (Raptr Inc., Mountain View, CA, USA, version 2.2.7_1951aba_46854) to later extract performance data, namely how far they got in the game (level and level section reached) and the total score they attained. After the gaming session, participants were asked to fill out the SSQ and SAM once again, and, for the first time, the FSS, the STSS, and the IPQ. They were also asked if they had played Thumper before and if they liked the game.

We chose 25 minutes as the duration of the play session based on studies by Tobin, Bisson, and Grondin (Bisson et al., 2012; Tobin et al., 2010), in which they noted that there seems to be an adaptation period when playing games during which players typically overestimate the duration of the play session. After this adaptation period, participants in these studies tended to underestimate the 
duration of the task. This could be an indication that some time is needed for a flow state to be achieved - especially when engaging in a novel task. There is no clear boundary to this adaptation period, but going from the observations of Tobin, Bisson, and Grondin, 25 minutes seemed like a safe time frame for participants to adjust to the game and enter a state of flow.

In all, 101 participants took part in the procedure, but one interrupted the gaming session after 21 minutes due to a feeling of queasiness and was thus excluded from the analysis.

\subsection{Analysis}

For the data analysis we used the software SYSTAT 13 (Systat Software Inc., San Jose, CA, USA version 13.00.05). For the comparison between conditions, we used $t$-tests for independent samples and, for the differences in cybersickness, valence,

Table 1.

Measures for different dependent variables in each of the two conditions, namely playing Thumper in VR and on a computer screen (2D).

\begin{tabular}{|c|c|c|c|c|}
\hline $\begin{array}{l}\text { Measures (flow \& flow-related } \\
\text { variables) }\end{array}$ & $\begin{array}{c}\text { VR } \\
\text { Mean (SD) }\end{array}$ & $\begin{array}{c}2 \mathrm{D} \\
\operatorname{Mean}(\mathrm{SD})\end{array}$ & $t$ & $p$ \\
\hline Flow (FSS) [ $1 \ldots 7$. & $5.42(1.13)$ & $5.08(0.87)$ & 1.68 & 0.095 \\
\hline Game challenge (FSS 14) [ [ $1 \ldots 9$. $]$ & $3 \cdot 5(1.89)$ & $4.5^{2}(1.61)$ & 2.91 & $0.004^{\mathrm{FDR}}$ \\
\hline $\begin{array}{l}\text { Achieved game level in } \\
\text { Thumper }\left[\begin{array}{lll}1 & \ldots & 37\end{array}\right]^{*}\end{array}$ & $25.84(6.44)$ & $22.61(6.20)$ & -2.42 & 0.017 \\
\hline Total score in Thumper & $102,391(49,930)$ & $75,610(37,493)$ & -2.91 & $0.005^{\mathrm{FDR}}$ \\
\hline Like game $[1 \ldots 7]$ & $5 \cdot 347(1.41)$ & $4.735(1.59)$ & -2.02 & 0.047 \\
\hline $\begin{array}{l}\text { Estimated duration of play } \\
\text { session (STSS) [real } \\
\text { duration }=25 \text { mins. }]\end{array}$ & $23: 12\left(8: 5^{2}\right)$ & $24: 45(8: 26)$ & 0.89 & 0.373 \\
\hline $\begin{array}{l}\text { Thinking about time (STSS) } \\
{[0 . . .10]}\end{array}$ & $2.406\left(2.5^{\circ}\right)$ & $2.032(1.87)$ & -0.85 & 0.399 \\
\hline $\begin{array}{l}\text { Speed of time passage (STSS) } \\
{\left[\begin{array}{l}0 . .10 \\
\text { 10 }]\end{array}\right.}\end{array}$ & $7 \cdot 322(2.14)$ & $7.244(1.78)$ & -0.19 & 0.843 \\
\hline Bodily awareness (STSS) [ 1 ...7 7$]$ & $3.8(1.46)$ & $3.62(1.43)$ & -0.19 & 0.534 \\
\hline $\begin{array}{l}\text { Emotional Valence }(\text { SAM }) \\
{\left[\begin{array}{lll}-4 & \ldots & 4\end{array}\right]^{* *}}\end{array}$ & $0.120(0.92)$ & $0.061(0.63)$ & -0.25 & 0.711 \\
\hline Arousal $(\mathrm{SAM})\left[\begin{array}{lll}-4 & \cdots & 4\end{array}\right]^{* *}$ & $0.460(1.05)$ & $0.55^{1}(0.74)$ & 0.49 & 0.620 \\
\hline
\end{tabular}

*The maximum of 37 levels is a result of the sum of the 15 sections of level 1 and the 22 sections of level 2 of Thumper. The maximum achieved level by our participants was 2-22.

**Difference between before and after the game session.

FDR, Significant differences after alpha adjustment according to the False Discovery Rate method. 
and arousal before and after the play session, $t$-tests for dependent samples and repeated-measures ANOVAs. Correlations were analyzed with Pearson's correlation coefficients. The false discovery rate (FDR) method, a multiple-comparisons correction procedure (Benjamini \& Hochberg, 1995), was used to control for multiple tests with initial significance levels set to $p<0.05$. The FDR correction was applied to significance tests for difference scores (VR, 2D) and correlations pertaining to the variables which are conceptually related to flow states (Tables 1 and 2). When statistically significant group differences were found, we calculated the effect sizes using Cohen's $d$. With the relatively large sample size of $n=100$ ( $n=50$ per condition) parametric tests are robust against violations of assumptions regarding nonnormal distribution which according to the Shapiro-Wilk test is the case in most of the variables. We therefore additionally report nonparametric test statistics (Mann-Whitney $U$ test, Wilxoxon, Spearman correlation) whenever we find a significant effect using parametric tests.

\section{Results}

\subsection{VRvs $2 D$}

Regarding the FSS sum score with a scale range between 1 and 7, Thumper elicited flow states in both conditions: 5.08 in 2D (SD: 0.87) and 5.42 in VR (SD: 1.13).

Table 2.

Pearson correlation coefficients $(r)$ and related $p$ values between Flow experience (FSS sum) and measures of variables conceptually related to flow across two conditions (VR, 2D) for $n=100$ subjects

\begin{tabular}{|c|c|c|}
\hline Measures [flow (FSS sum) \& flow-related variables] & $r$ & $p$ \\
\hline Achieved game level in Thumper $\left[\begin{array}{lll}1 & . . & 37\end{array}\right]^{*}$ & 0.356 & $0.001^{\mathrm{FDR}}$ \\
\hline Total score in Thumper & 0.416 & $0.001^{\mathrm{FDR}}$ \\
\hline Like game $[1 \ldots 7]$ & 0.600 & $0.001^{\mathrm{FDR}}$ \\
\hline $\begin{array}{l}\text { Estimated duration of play session (STSS) [real dura- } \\
\text { tion }=25 \mathrm{mins}]\end{array}$ & -0.118 & 0.243 \\
\hline Thinking about time (STSS) $[0 \ldots 10]$ & $-0.5^{24}$ & $0.001^{\mathrm{FDR}}$ \\
\hline Speed of time passage (STSS) $[0 . . .10]$ & $0.35^{1}$ & $0.001^{\mathrm{FDR}}$ \\
\hline Bodily awareness (STSS) [ 1 ... 7$]$ & 0.144 & 0.153 \\
\hline Emotional Valence (SAM) $[-4 \ldots 4]^{* *}$ & 0.405 & $0.001^{\mathrm{FDR}}$ \\
\hline Arousal (SAM) $[-4 \ldots 4]^{* *}$ & -0.089 & 0.382 \\
\hline
\end{tabular}

*, The maximum of 37 levels is a result of the sum of the 15 sections of level 1 and the 22 sections of level 2 of Thumper. The maximum achieved level by our participants was $2-22$.

**, Difference between before and after the game session.

FDR, Significant differences after alpha adjustment according to the False Discovery Rate method. 
The difference between conditions is not significant $\left(t_{98}=1.687, p=0.095\right)$. All descriptive data and the inferential statistics can be seen in Table 1 .

Participants in the VR condition found the game easier (game challenge; FSS 14) than those who played on a screen $\left(t_{98}=2.91, p=0.004\right.$; significant after FDR correction, Cohen's $d=0.581$; Mann-Whitney $U: 1669.5 ; p=0.003$ ), which reflects the objective measures of performance. Namely, participants who played in VR both reached higher levels (and level sections) in the game $t_{89}=-2.42$, $p=0.017$, not significant after FDR correction) and attained higher scores $\left(t_{86}=-2.91, p=0.005\right.$; FDR-corrected, Cohen's $d=0.606$; Mann-Whitney $U$ : $733.0 ; p=0.011$ ) than participants who played in 2D. There is a tendency for a difference between the conditions with regard to the question of how much they 'liked the game' ( $t_{96}=-2.02, p=0.047$; not significant after FDR adjustment).

There was no significant difference between conditions in duration estimates of the play session $\left(t_{98}=0.857, p=0.394\right)$, how often participants thought about time $\left(t_{98}=-0.846, p=0.399\right)$, and how fast time passed in their experience $\left(t_{98}=-0.198, p=0.843\right)$. Subjects estimate the duration of the 25-minute game quite accurately (mean: 23:58 min.; mean 2D: 24:45 min.; mean VR: 23:12 min). According to one-sample $t$-tests, the slight average underestimations from the objective 25 minutes of game time are not significant (VR: $t_{49}=1.44, p=0.157$; 2D: $\left.t_{49}=-0.21, p=0.831\right)$. Regarding the 10-cm visual analog scales, players thought that time had passed quickly (mean 2D: 7.244; mean VR: 7.322) and they did not think much about time (mean 2D: 2.032; mean VR: 2.406). Importantly, the two time variables of 'duration estimate' and 'passage of time' are not correlated with each other (2D: $r=-0.141, p=0.330$; VR: $r=-0.045, p=0.756)$. A strong negative correlation between how often subjects thought about time and the passage of time is found in the VR condition (Pearson's $r=-0.540, p<0.001$; Spearman's $r=-0.523, p<0.001)$, i.e. the more individuals thought about time, the slower they experienced time passage. This correlation did not show up in the $2 \mathrm{D}$ condition $(r=-0.202, p=0.160)$. Thinking about time was not related to the duration estimate in either of the two conditions (VR: $r=0.214, p=0.135$; 2D: $r=0.049 ; p=0.736$ ).

Bodily awareness was similar in both conditions $\left(t_{98}=-0.624, p=0.267\right)$. There were no significant differences between conditions in emotional valence $\left(t_{97}=-0.371, p=0.711\right)$ and arousal $\left(t_{97}=0.497, p=0.620\right)$ concerning the difference between before and after playing Thumper in each of these variables.

As expected, participants who played Thumper in VR reported a stronger feeling of presence in the virtual world than those who played on a screen $\left(t_{98}=-2.516\right.$, $p=0.007$; Mann-Whitney $U: 913.0 ; p=0.01)$. Finally, there was no difference between conditions in the experience of cybersickness, neither before nor after the gaming session $\left(t\right.$ before ${ }_{98}=1.084, p=0.141$; $_{\text {tafter }}{ }_{98}=0.653, p=0.742$; $t$ difference, ${ }_{98}=1.480, p=0.929$ ). . The cybersickness values were significantly higher in both conditions after playing than before playing Thumper $\left(F_{1,99}=26.37\right.$, 
$p<0.001$; Wilcoxon $Z$ : 4.734, $p<0.001$ ), but values were low to negligible (VR: $M=3.94, \mathrm{SD}=3.695 ; 2 \mathrm{D}: M=4.48, \mathrm{SD}=4.528 ;$ maximum possible score $=48$ ). Additionally, $26 \%$ of participants in the VR condition reported feeling less cybersickness after playing the game, while in the $2 \mathrm{D}$ condition $14 \%$ of participants reported the same.

When inspecting possible gender differences for the state variables assessed after playing Thumper, for the VR and 2D conditions, with one exception there are no significant differences $(p>0.1)$. Only in the VR condition there is a tendency $\left(t_{42}=-2.12, p=0.040\right)$ for female participants to reach a higher overall level in the game than male participants.

\subsection{Interrelations with Flow}

To not overload this section with both Pearson's and Spearman's correlation statistics, we present only Pearson's correlation coefficients and indicate with an asterisk $\left(^{*}\right)$ when the correlation coefficient with Spearman was significant as well. Correlation analyses show that the more flow (FSS sum) participants experienced the less they thought about time $\left(r=-0.524^{*}, p<0.001\right.$, FDR-corrected; VR: $\left.r=-0.638^{*}, p<0.001 ; 2 \mathrm{D}: r=-0.391, p=0.005\right)$ and the faster time passed for them $\left(r=0.351^{*}, p<0.001\right.$, FDR-corrected). This latter effect was driven mainly by the VR condition (VR: $r=0.510^{*}, p<0.001$ ) as there was no significant association in the 2D condition (2D: $r=0.200, p=0.184$ ). The participants' duration estimations of the play session in minutes and seconds, however, did not correlate with their flow experience $(r=-0.118, p=0.243$; VR: $r=-0.158, p=0.275$; 2D: $r=-0.034, p=0.814$ ).

Reported flow states were related to performance and appraisal of playing Thumper. The more flow experience during the game, the higher the achieved game level $\left(r=0.356^{*}, p<0.001\right.$, FDR-corrected). This association is driven mainly by the VR condition (VR: $r=0.417^{*}, p=0.005$; 2D: $r=0.174, p=0.253$ ). The more reported flow, the higher the total score in Thumper $\left(r=0.407^{*}\right.$, $p<0.001$, FDR-corrected; VR: $r=0.412^{*}, p<0.004$; 2D: $\left.r=0.332, p=0.024\right)$, and the more players liked the game $\left(r=0.600^{*}, p<0.001\right.$, FDR-corrected; VR: $\left.r=0.602^{*}, p<0.001 ; 2 \mathrm{D}: r=0.596^{*}, p<0.001\right)$.

The level of experienced flow was associated with felt emotions (SAM valence): the more flow, the higher the increase of positive affect after vs before the game $\left(r=0.405^{*}, p<0.001\right.$, FDR-corrected; VR: $r=0.389^{*}, p<0.005$; 2D: $r=0.443^{*}$, $p<0.001)$. No significant correlation appeared between flow experience and subjective arousal level (SAM arousal: $r=-0.089, p=0.382$ ), and flow and bodily awareness $(r=0.144, p=0.153)$.

The feeling of presence also correlated positively with flow experience $\left(r=0.389^{*}, p<0.001\right.$, FDR-corrected). Regarding the two conditions, this correlation appeared only in the VR condition (VR: $r=0.462^{*}, p<0.001 ; 2 \mathrm{D}: r=0.237$, 
$p=0.097)$. We did not find a significant correlation between flow proneness (SFPQ) and the experienced level of flow overall $(r=0.153, p=0.128)$, nor independently in any of the conditions (VR: $r=0.233, p=0.104$; 2D: $r=0.079$, $p=0.583)$. Cybersickness correlated negatively with flow: the more cybersickness participants felt, the less flow they experienced $\left(r=-0.309^{*}, p=0.002\right)$.

\subsection{Gaming Experience}

As reported above, we divided the sample into two groups according to gaming experience: The "gamers" group $(n=69)$ and the "non-gamers" group $(n=31)$. We could not find significant differences between these groups, with the exception of the change in level of arousal (SAM) between before and after the gaming session $\left(t_{96}=2.388, p=0.019, d=0.523\right.$; not significant after FDR correction). This difference was larger among non-gamers than among gamers.

\section{Discussion}

We assessed the experience of flow and time perception with the video game Thumper in two conditions, in VR and on a computer screen (2D). Thumper elicited flow (FSS sum) in participants in both conditions, even though none of the participants had played the game before. Participants scored 5.08 points in 2D and 5.42 in VR of a maximum of seven points in FSS. The experience of flow was related to subjective time. The more flow participants reported having had during the game, the less they thought about time and the faster time passed subjectively. The results align with those of Keller and Bless (2008) with regard to time perception and flow and, in addition, they reveal that the experienced flow correlated positively with a better player performance in the game. Keller and Bless could not show this, given that they used different versions of Tetris that were either too easy, too hard, or automatically adapted to the player's skill level, while we used the same version of Thumper for every participant. In addition, experienced flow correlated with 'fun', i.e., liking the game and being in a better mood after the game than before.

One common adage among video game designers is "follow the fun". This means that, if you are designing a video game, you should prioritize the elements that players enjoy over those that they do not, even if the latter align better with your initial creative vision. If it is true that time flies when you are having fun, then game designers could just as well say "follow the flow". 'Fun' is difficult to define and measure (cf. Klarkowski et al., 2015), but a useful approximation are the two scales of liking the game and mood state before vs. after the game (SAM valence). We show empirical evidence that 'fun,' understood in this way, correlated with the experienced flow, which in turn was related to a faster passage of time.

In the original validation study of the scale by Rheinberg and colleagues, the highest flow value was 5.16 - found in graffiti artists (Rheinberg et al., 2003). 
Rheinberg and Vollmeyer (2003) also conducted a study with the video game Roboguard in different difficulty settings. In Roboguard players control a spaceship and have to avoid incoming rockets - if the ship is hit, it is destroyed and the game restarts. The objective is to survive for as long as possible. The maximum flow value in this study was of 4.8 points. The game Thumper is thus highly effective in inducing flow states and can be recommended for further use in future studies, especially considering that many of our participants had little to no experience with video games $-31 \%$ reported never having played a video game before or playing less than once a week and never having played with a higher frequency.

Participants played better in the VR condition than in 2D as they attained higher scores. This is reflected on their subjective experience, as shown by the lower scores on the challenge item of the flow questionnaire (FSS 14) of participants who played in VR, meaning that playing in VR felt easier than playing in 2D. Some of the found associations between levels of experienced flow and the other variables, which are conceptually related to flow, were mainly driven by correlations in the VR condition. One possible explanation for these findings is that reacting to the incoming objects (lights, curves, spikes) on Thumper's track is easier when looking at the stereoscopic image of a VR HMD than at the two-dimensional image of a screen. One would naturally expect players to be better at estimating the distance to and velocity of these objects if they can make use of their depth perception, which would lead to a better performance.

Additionally, participants in VR felt significantly more present in the virtual world. This enhanced experience of presence could have helped players be more attentive to the game - and consequently less distracted by stimuli unrelated to it - and achieve higher levels of concentration (one of the main aspects of flow).

On the question about how long the play session lasted, which participants had to answer with a value in minutes and seconds, there was no significant underestimation. On average, participants estimated the 25-minute play session to have lasted 24 minutes. One would reasonably expect participants to underestimate the duration of the play session if they experienced time as moving faster than usual and thought less about time. The reason why there was no observable underestimation might be that participants took the knowledge of time passing faster in experience into consideration, since games are popularly known to have this effect, and compensated their estimations accordingly. This reasoning is corroborated by the fact that the two variables 'duration estimate' and 'passage of time' do not correlate. Empirical work has actually consistently shown the seemingly paradoxical dissociation between passage of time and duration estimation (DroitVolet \& Wearden, 2016; Weiner et al., 2016). It has therefore been suggested that these two time judgments are dependent upon different processes. In our study, individuals simultaneously had the impression of a fast passage of the game session and did not attend much to time. However, when asked to judge the game's duration, they were accurate in clock time. The two variables 'passage of time' 
(participants felt that time had passed quickly) and 'thinking about time' (they did not think much about time while gaming) are thus components of the gameinduced flow state. As mentioned in the Methods section, we were aware that this could happen before the experiment, which is why we decided to ask participants first about the duration and after that about how fast time passed in their experience and how often they thought about time. We phrased the question in a way that appealed to their gut feeling of time, following the study conducted by Tobin et al. (2010) ("Intuitively, without thinking about it, the gameplay session lasted minutes and seconds"). Unfortunately, our efforts did not have the effect we hoped for. Given that participants stated that time passed faster in their experience the more flow they reported, it is likely that the compensation we were trying to avoid did take place. Future experiments should take this result into consideration or have to employ longer playing times.

Another possible explanation for the mismatch between time estimates and the variable 'passage of time' could relate to the effects of self-motion on time perception. Studies have shown that duration estimates increase with velocity while moving through space (Brehmer, 1970; van Rijn, 2014; Weber et al., 2020). Weber and coworkers (2020) specifically showed that this effect can take place in a VR environment. Participants in this study underestimated the duration of trials overall, but their estimates increased as a function of velocity. Since Thumper is a fast-paced game that presumably elicits a feeling of self- motion, our participants' time estimates could have been affected, counteracting the effects of flow on time estimation (i.e., compensating for underestimations). This could be tested in further experiments.

With regard to the SFPQ, we did not observe a significant correlation between flow proneness and experienced flow as reported with the FSS. This could be due to the broad categories used in the SFPQ's subscales, such as the experience of flow in domestic chores - which can include disparate tasks like vacuuming or doing the laundry. The domains of activity analyzed by the SFPQ are difficult to compare to an activity like playing a video game. The lack of correlations between flow and flow proneness put the utility of the SFPQ as a tool for measuring flow into question.

Finally, our results could be helpful for clinical psychology. A study by Kühn and coworkers (2018), for instance, showed that playing the video game Boson $\mathrm{X}$ for six weeks can reduce rumination and enhance cognitive ability in depressed individuals. Boson $\mathrm{X}$ has very similar characteristics to Thumper, in that players control a character from a third-person perspective with the camera fixed behind it. The character runs automatically through a tunnel and players need to press one of three keys (up, left, and right on the keyboard) to surmount obstacles. Individuals with Major Depressive Disorder often report that the passage of time drastically slows down in their experience (Vogel et al., 2018). The state of flow elicited by games like Thumper could help ameliorate this symptom of depression 
by accelerating the passage of time while also helping reduce rumination. But these claims require further examination.

\section{Conclusion}

Video games, as this paper has argued, are a prototypical flow activity that offers clear goals, can be completed, and provides immediate feedback. When players enter the flow state they experience high levels of concentration, effortless involvement, a sense of control, and the loss of the senses of time and self. The present study provides some of the first quantitative experimental evidence that time perception is affected by game-induced flow states: The more flow someone experiences, the less they think about time, and the faster time passes for them. The study also shows that playing Thumper in VR leads players to perform better and experience the game as easier than when playing on a computer screen.

The experiential aspects of flow are harder to scrutinize than the outward behavioral characteristics of the activity, which is perhaps why phenomena like time perception in flow states have not been the focus of many quantitative studies. In addition, the study of time perception has only started to flourish in the past two decades, which might also explain why there are few studies on flow that focus on this particular aspect. Flow has so far been more commonly studied as a qualitative concept with attention distributed among all of its characteristics, and less so with quantitative focus on one particular aspect. Selectively inspecting the experiential aspects of flow can further our understanding of this altered state of consciousness and may even help us find applications of flow in clinical contexts.

\section{Acknowledgments}

This study was funded by the EU, Horizon 2020 Framework Program, FET Proactive (VIRTUALTIMES consortium, grant agreement Id: 824128 to Marc Wittmann). VIRTUALTIMES - Exploring and modifying the sense of time in virtual environments - includes the following groups with the principal investigators Kai Vogeley (Cologne), Marc Wittmann (Freiburg), Anne Giersch (Strasbourg), Marc Erich Latoschik, Jean-Luc Lugrin (Würzburg), Giulio Jacucci, Niklas Ravaja (Helsinki), Xavier Palomer, and Xavier Oromi (Barcelona).

\section{Note}

1. This principle is known as Bushnell's Law among game designers, since it is attributed to Atari founder Nolan Bushnell, who allegedly said that "[a]ll the best games are easy to learn and difficult to master. They should reward the first quarter and the hundredth" (in Bogost, 2009). 


\section{References}

Agarwal, R., \& Karahanna, E. (2000). Time flies when you're having fun: cognitive absorption and beliefs about information technology usage. MIS Q., 24, 665-694. doi: 10.2307/3250951.

Alvarez Igarzábal, F. (2019). Time and space in video games: a cognitive-formalist approach. Bielefeld, Germany: transcript Verlag. doi: 10.14361/9783839447130.

Alvarez Igarzábal, F. (2020). Experiencing the passage of time in video games. Presented at 13th Int. Philosophy of Computer Games Conference, 2019, St. Petersburg, Russia. http://gamephilosophy.org/conference-manuscripts/.

Baron, S. (2012). Cognitive flow: The psychology of great game design. https://www.gamasutra.com/ view/feature/166972/cognitive_flow_the_psychologyof_php.

Benjamini, Y., \& Hochberg, Y. (1995). Controlling the false discovery rate: a practical and powerful approach to multiple testing. J. R. Stat. Soc. B, 57, 289-300.

Bisson, N., \& Grondin, S. (2013). Time estimates of internet surfing and video gaming. Timing Time Percept. 1, 39-64. doi: 10.1163/22134468-00002002.

Bisson, N., Tobin, S., \& Grondin, S. (2012). Prospective and Retrospective time estimates of children: a comparison based on ecological tasks. PLoS ONE, 7, e33049. doi: 10.1371/journal. pone.0033049.

Block, R. A., \& Zakay, D. (1997). Prospective and retrospective duration judgments: A meta-analytic review. Psychon. Bull. Rev., 4, 184-197. doi: 10.3758/BF03209393.

Bogost, I. (2009). Persuasive games: familiarity, habituation, and catchiness. https://www.gamasutra. com/view/feature/3977/persuasive_games_familiarity_php.

Bradley, M. M., \& Lang, P. J. (1994). Measuring emotion: The self-assessment manikin and the semantic differential.J. Behav. Ther. Exp. Psychiatry, 25, 49-59. doi: 10.1016/0005-7916(94)90063-9.

Brehmer, B. (1970). Note on the effect of velocity on perceived duration. Scand. J. Psychol., 11, 157160. doi: $10.1111 /$ j.1467-9450.1970.tb00730.x.

Chen, J. (2006). Flow in games. A Jenova Chen MFA thesis. http://www.jenovachen.com/flowingames/.

Christandl, F., Mierke, K., \& Peifer, C. (2018). Time flows: Manipulations of subjective time progression affect recalled flow and performance in a subsequent task.J. Exp. Soc. Psychol., 74, 246-256. doi: 10.1016/j.jesp.2017.09.015.

Csikszentmihalyi, M. (2000). Beyond boredom and anxiety (25th anniversary ed). San Francisco, CA, USA: Jossey-Bass Publishers.

Csikszentmihalyi, M. (2009). Flow: The psychology of optimal experience (Nachdr.). New York, NY, USA: Harper \& Row.

Csikszentmihalyi, M., \& Larson, R. (2014). Validity and reliability of the experience-sampling method. In M. Csikszentmihalyi , Flow and the foundations of positive psychology. The collected works of Mihaly Csikszentmihalyi (pp. 35-54). Dordrecht, The Netherlands: Springer. doi: 10.1007/978-94-017-9088-8_3.

Csikszentmihalyi, M., \& Rathunde, K. (1992). The measurement of flow in everyday life: Toward a theory of emergent motivation. In J. E. Jacobs (Ed.), Nebraska Symposium on Motivation, 1992: Developmental perspectives on motivation (pp. 57-97). Lincoln, NE, USA: University of Nebraska Press.

Droit-Volet, S., \& Wearden, J. (2016). Passage of time judgments are not duration judgments: evidence from a study using experience sampling methodology. Front. Psychol., 7, 176. doi: 10.3389/ fpsyg.2016.00176. 
Engeser, S., Rheinberg, F., Vollmeyer, R., \& Bischoff, J. (2005). Motivation, Flow-Erleben und Lernleistung in universitären Lernsettings. Z. Pädagog. Psychol., 19, 159-172. doi: 10.1024/1010-0652.19.3.159.

Ermi, L., \& Mäyrä, F. (2005). Fundamental components of the gameplay experience: analysing immersion. http://www.digra.org/wp-content/uploads/digital-library/06276.41516.pdf.

Faiola, A., \& Voiskounsky, A. E. (2007). Flow experience of MUD players: investigating multi-user dimension gamers from the USA. In D. Schuler (Ed.), Online Communities and Social Computing (pp. 324-333). Berlin, Germany: Springer. doi: 10.1007/978-3-540-73257-0_36.

Ghani, J. A., \& Deshpande, S. P. (1994). Task characteristics and the experience of optimal flow in human-computer interaction.J. Psychol., 128, 381-391. doi: 10.1080/00223980.1994.9712742.

Hektner, J. M., Schmidt, J. A., \& Csikszentmihalyi, M. (2007). Experience sampling method. Measuring the quality of everyday life. Thousand Oaks, CA, USA: SAGE Publications, Inc. doi: $10.4135 / 9781412984201$.

Hoffman, D. L., \& Novak, T. P. (1996). Marketing in hypermedia computer-mediated environments: conceptual foundations. J. Market., 60, 50-68. doi: 10.2307/1251841.

Jackson, S. A., \& Marsh, H. W. (1996). Development and validation of a Scale to Measure Optimal Experience: The Flow State Scale. J. Sport Exerc. Psychol., 18, 17-35. doi: 10.1123/jsep.18.1.17.

Jennett, C., Cox, A. L., Cairns, P., Dhoparee, S., Epps, A., Tijs, T., \& Walton, A. (2008). Measuring and defining the experience of immersion in games. Int. J. Hum. Comput. Stud., 66, 641-661. doi: 10.1016/j.ijhcs.2008.04.004.

Jin, S.-A. A. (2012). "Toward Integrative Models of Flow": Effects of performance, skill, challenge, playfulness, and presence on flow in video games. J. Broadcast. Electron. Media, 56, 169-186. doi: 10.1080/08838151.2012.678516.

Jokic, T., Zakay, D., \& Wittmann, M. (2018). Individual differences in self-rated impulsivity modulate the estimation of time in a real waiting situation. Timing Time Percept., 6, 71-89. doi: $10.1163 / 22134468-00002101$.

Keller, J., \& Bless, H. (2008). Flow and regulatory compatibility: an experimental approach to the flow model of intrinsic motivation. Personal. Soc. Psychol. Bull., 34, 196-209. doi: $10.1177 / 0146167207310026$.

Kennedy, R. S., Lane, N. E., Berbaum, K. S., \& Lilienthal, M. G. (1993). Simulator sickness questionnaire: an enhanced method for quantifying simulator sickness. Int. J. Aviat. Psychol., 3, 203-220. doi: 10.1207/s15327108ijap0303_3.

Klarkowski, M., Johnson, D., Wyeth, P., Smith, S., \& Phillips, C. (2015). Operationalising and measuring flow in video games. OzCHI '15: Proceedings of the Annual Meeting of the Australian Special Interest Group for Computer Human Interaction (pp. 114-118). doi: 10.1145/2838739.2838826.

Kühn, S., Berna, F., Lüdtke, T., Gallinat, J., \& Moritz, S. (2018). Fighting depression: action video game play may reduce rumination and increase subjective and objective cognition in depressed patients. Front. Psychol., 9, 129. doi: 10.3389/fpsyg.2018.00129.

Larson, R., \& Csikszentmihalyi, M. (2014). The experience sampling method. In M. Csikszentmihalyi , Flow and the foundations of positive psychology. The collected works of Mihaly Csikszentmihalyi (pp. 21-34). Dordrecht, The Netherlands: Springer. doi: 10.1007/978-94-017-9088-8_2.

Luthman, S., Bliesener, T., \& Staude-Müller, F. (2009). The effect of computer gaming on subsequent time perception. Cyberpsychology, 3. 2. https://cyberpsychology.eu/article/view/4221/3263.

Michailidis, L., Balaguer-Ballester, E., \& He, X. (2018). Flow and Immersion in video games: the aftermath of a conceptual challenge. Front. Psychol., 9, 1682. doi: 10.3389/fpsyg.2018.01682. 
Nunnally, J. C. (1978). Psychometric theory (2nd ed). New York, NY, USA: McGraw-Hill.

Nuyens, F. M., Kuss, D. J., Lopez-Fernandez, O., \& Griffiths, M. D. (2020). The potential interaction between time perception and gaming: a narrative review. Int. J. Ment. Health Addict., 18, 1226 1246. doi: 10.1007/s11469-019-00121-1.

Privette, G. (1983). Peak experience, peak performance, and flow: A comparative analysis of positive human experiences.J. Pers. Soc. Psychol., 45, 1361-1368. doi: 10.1037/0022-3514.45.6.1361.

Rau, P.-L. P., Peng, S.-Y., \& Yang, C.-C. (2006). Time distortion for expert and novice online game players. Cyberpsychol. Behav., 9, 396-403. doi: 10.1089/cpb.2006.9.396.

Rheinberg, F., \& Vollmeyer, R. (2003). Flow-Erleben in einem Computerspiel unter experimentell variierten Bedingungen. Z. Psychol., 211, 161-170. doi: 10.1026//0044-3409.211.4.161.

Rheinberg, F., Vollmeyer, R., \& Engeser, S. (2003). Die Erfassung des Flow-Erlebens. In J. StiensmeierPelster \& F. Rheinberg (Eds), Diagnostik von Motivation und Selbstkonzept (Test und Trends N.F. 2) (pp. 261-279). Göttingen, Germany: Hogrefe.

Salen, K., \& Zimmerman, E. (2003). Rules of play: Game design fundamentals. Cambridge, MA, USA: MIT Press.

Sanders, T., \& Cairns, P. (2010). Time perception, immersion and music in videogames. BCS '10: Proceedings of the 24th BCS Interaction Specialist Group Conference (pp.. 160-167).

Schell, J. (2008). The art of game design: A book of lenses. Amsterdam, The Netherlands, Elsevier: Morgan Kaufmann.

Schubert, T. W. (2003). The sense of presence in virtual environments: A three-component scale measuring spatial presence, involvement, and realness. Z. Medienpsychol., 15, 69-71. doi: 10.1026//1617-6383.15.2.69.

Schubert, T., Friedmann, F., \& Regenbrecht, H. (2001). The experience of presence: factor analytic insights. Presence (Camb.), 10, 266-281. doi: 10.1162/105474601300343603.

Sevinc, V., \& Berkman, M. I. (2020). Psychometric evaluation of Simulator Sickness Questionnaire and its variants as a measure of cybersickness in consumer virtual environments. Appl. Ergon., 82, 102958. doi: 10.1016/j.apergo.2019.102958.

Shernoff, D. J., Hamari, J., \& Rowe, E. (2014). Measuring flow in educational games and gamified learning environments. In J. Viteli \& M. Leikomaa (Eds), Proceedings of EdMedia 2014 World Conference on Educational Media and Technology (pp. 2276-2281). Tampere, Finland: Association for the Advancement of Computing in Education (AACE).

Sweetser, P., Johnson, D., \& Wyeth, P. (2012). Revisiting the GameFlow model with detailed heuristics. J. Creat. Technol., 3, 1-16.

Sweetser., \& Wyeth, P. (2005). GameFlow: a model for evaluating player enjoyment in games. Comput. Entertain., 3, 3. doi: 10.1145/1077246.1077253.

Takatalo, J., Häkkinen, J., Kaistinen, J., \& Nyman, G. (2010). Presence, Involvement, and Flow in Digital Games. In R. Bernhaupt (Ed.), Evaluating User Experience in Games (pp. 23-46). Springer London. doi.org/10.1007/978-1-84882-963-3_3.

Tobin, S., Bisson, N., \& Grondin, S. (2010). An ecological approach to prospective and retrospective timing of long durations: a study involving gamers. PLoS ONE, 5, e9271. doi: 10.1371/journal. pone.0009271.

Tobin, S., \& Grondin, S. (2009). Video games and the perception of very long durations by adolescents. Comput. Hum. Behav., 25, 554-559. doi: 10.1016/j.chb.2008.12.002.

Treisman, M. (2013). The information-processing model of timing (Treisman, 1963): Its sources and further development. Timing Time Percept., 1, 131-158. doi: 10.1163/22134468-00002017. 
Trevino, L. K., \& Webster, J. (1992). Flow in computer-mediated communication: electronic mail and voice mail evaluation and impacts. Commun. Res., 19, 539-573. doi: 10.1177/009365092019005001.

Ullén, F., de Manzano, Ö., Almeida, R., Magnusson, P. K. E., Pedersen, N. L., Nakamura, J., Csíkszentmihályi, M., \& Madison, G. (2012). Proneness for psychological flow in everyday life: Associations with personality and intelligence. Pers. Individ. Dif., 52, 167-172. doi: 10.1016/j. paid.2011.10.003.

van Rijn, H. (2014). It's time to take the psychology of biological time into account: speed of driving affects a trip's subjective duration. Front. Psychol., 5, 1028. doi: 10.3389/fpsyg.2014.01028.

Vogel, D. H. V., Krämer, K., Schoofs, T., Kupke, C., \& Vogeley, K. (2018). Disturbed experience of time in depression - evidence from content analysis. Front. Hum. Neurosci., 12, 66. doi: 10.3389/ fnhum.2018.00066.

Voiskounsky, A. E., Mitina, O. V., \& Avetisova, A. A. (2004). Playing Online games: Flow experience. PsychNology Journal, 2, 259-281.

Weber, S., Weibel, D., \& Mast, F. W. (2020). How self-motion in virtual reality affects the subjective perception of time. Timing Time Percept., 8, 119-136. doi: 10.1163/22134468-20191152.

Webster, J., Trevino, L. K., \& Ryan, L. (1993). The dimensionality and correlates of flow in humancomputer interactions. Comput. Hum. Behav., 9, 411-426. doi: 10.1016/0747-5632(93)90032-N.

Weibel, D., Stricker, D., \& Wissmath, B. (2012). The use of a virtual learning centre in the context of a university lecture: factors influencing satisfaction and performance. Interact. Learn. Environ., 20, 77-87. doi: 10.1080/10494821003755502.

Weibel, D., \& Wissmath, B. (2011). Immersion in computer games: the role of spatial presence and flow. Int. J. Comput. Games Technol., 2011, 282345. doi: 10.1155/2011/282345.

Weiner, L., Wittmann, M., Bertschy, G., \& Giersch, A. (2016). Dispositional mindfulness and subjective time in healthy individuals. Front. Psychol., 7, 786. doi: 10.3389/fpsyg.2016.00786.

Witowska, J., Schmidt, S., \& Wittmann, M. (2020). What happens while waiting? How self-regulation affects boredom and subjective time during a real waiting situation. Acta Psychol., 205, 103061. doi: 10.1016/j.actpsy.2020.103061.

Wittmann, M. (2015). Modulations of the experience of self and time. Consc. Cogn., 38, 172-181. doi: 10.1016/j.concog.2015.06.008.

Wittmann, M. (2018). Altered states of consciousness: Experiences out of time and self. Cambridge, MA, USA: MIT Press.

Wood, R. T. A., \& Griffiths, M. D. (2007). Time loss whilst playing video games: is there a relationship to addictive behaviours? Int. J. Ment. Health Addict., 5, 141-149. doi: 10.1007/s11469-006-9048-2.

Wood, R. T. A., Griffiths, M. D., \& Parke, A. (2007). Experiences of time loss among videogame players: an empirical study. CyberPsychology \& Behavior, 10, 38-44. doi: 10.1089/cpb.2006.9994.

Wood, R. T. A., Gupta, R., Derevensky, J. L., \& Griffiths, M. (2004). Video game playing and gambling in adolescents: common risk factors. Journal of Child \& Adolescent Substance Abuse, 14, 77-100. doi: 10.1300/J029v14n01_05.

Zakay, D., \& Block, R. A. (1997). Temporal cognition. Curr. Dir. Psychol. Sci., 6, 12-16. doi: 10.1111/1467-8721.ep11512604. 